\title{
The Mothering of Conduct Problem and Normal Children in Spain and the USA: Authoritarian and Permissive Asynchrony
}

\author{
Robert G. Wahler ${ }^{1}$ and M. Angeles Cerezo ${ }^{2}$ \\ ${ }^{1}$ University of Tennessee \\ ${ }^{2}$ Universidad de Valencia
}

\begin{abstract}
Ninety-two clinic-referred and nonclinical mother-child dyads in Spain and the USA were observed in their home settings under naturalistic conditions for a total of 477 hours. Children in the clinic-referred dyads were considered troubled because of conduct problems. The observations were aimed at assessing two forms of mother-child asynchrony, either of which was expected to differentiate clinic referred from nonclinical dyads. Authoritarian asynchrony was defined as a mother's indiscriminate use of aversive reactions to her child, whereas the permissive form entailed indiscriminate positive reactions. Results showed the American mothers to generate more permissive asynchrony, whereas the Spanish mothers were inclined in the authoritarian direction. Only authoritarian asynchrony differentiated the clinical versus nonclinical dyads in each country. Discussion was centered on the greater salience of aversive as opposed to positive maternal attention, and cultural differences between countries that might have accounted for the different parenting styles. Keywords: asynchrony, conduct-problem children, naturalistic observation, SOC III
\end{abstract}

Se observaron a noventa y dos díadas madre-hijo clínicas y no clínicas en España y USA en el hogar durante 477 horas en total. Los niños de las díadas clínicas se consideraron desajustados por sus problemas de conducta. El objetivo era evaluar dos formas de asincronía madre-niño, que se esperaba diferenciaran las díadas clínicas de las no-clínicas. La "asincronía autoritaria" se definió como el uso materno de reacciones aversivas indiscriminadas hacia el niño, y la "asincronía permisiva" como reacciones indiscriminadas pero positivas. Los resultados mostraron que las madres americanas generaban más asincronía permisiva y las españolas más asincronía autoritaria. Solo la asincronía autoritaria diferenciaba las díadas por su status: clínico versus no clínico en ambos países. La discusión se centró en la mayor saliencia de la atención aversiva frente a la positiva y en aspectos culturales que pueden dar cuenta de los diferentes estilos parentales.

Palabras clave: asincronía, niños con problemas conductuales, observación naturalista, SOC III

The research conducted in Spain was supported by grants DGICYT PS94-0192 \& PB97-1394.

Correspondence should be addressed to M. Angeles Cerezo, Unidad de Investigación "Agresión y Familia”, Departamento de Psicología, Universidad de Valencia, Avda. Blasco Ibañez, 21, 46010 Valencia (Spain). E-mail: angeles.cerezo@uv.es 
The role of parenting in the formation of a child's social behavior has been outlined in many empirical studies, and that role has also been a focal point of research on the youngster's antisocial behavior-conduct problems in particular (see the review by Kazdin, 1987; Patterson, 2002). By and large, the direct moment-to-moment influence of parenting involves the child's mother, since that parent is the principal caregiver in most families and, therefore, the parent who generates most of these moment-to-moment experiences with the child (Patterson, 1982). Thus, this direct influence on child behavior is usually exercised by mothers and it is their parenting that becomes a focal point of inquiry. These inquiries show that mothering amounts to a practice in which her affection, discipline, teaching, playing, working, listening, and watching are orchestrated in reference to her child's various behaviors. This "orchestration" is important because her contingent arrangement of these events in reference to child behavior is more important than the distribution of these maternal behaviors over time (Bretherton \& Waters, 1985; Maccoby \& Martin, 1983; Westermann \& Havstad, 1982). When the orchestration fails and mother and child are "out of synch" with one another, they appear to be preoccupied with other matters, and they are likely to engage one another in disputes over leadership roles in their social interactions (see Cerezo \& Pons-Salvador, 1996; Patterson, 2002; Patterson, Reid, \& Dishion, 1992; Wahler, 1990). Out of such asynchronous patterns, the two parties lose respect for one another and the child is apt to move onto a path of socialization largely directed by extra family influences and the child's own temperament (Kopp, 1982; Lytton, 1990). Of course, this path is classic in the development of more serious outgrowths of child conduct problems (see Loeber \& Stouthamer-Loeber, 1986; Patterson, 2002).

Degree of synchrony in a mother-child relationship reflects the mother's style of parenting in contrast to her more specific practices. In line with the arguments presented by Darling and Steinberg (1993), style can be viewed as a global phenomenon independent of the content or goals of specific parent behaviors. Thus, a mother's statements of approval to her child or her demands that her child begin a time-out are practice examples, whereas synchrony is a more abstract entity referring to her timing of these responses. When a mother's style is asynchronous, she is mistiming her reactions and approaches so that her various responses are both inconsistent and inappropriate with respect to her child's array of responses. Within this chaotic class of dyadic mismatches, coercive patterns of mother-child exchange can materialize and may become social foundations for the child's antisocial behavior (Patterson, 1992; Vuchinich, Bank, \& Patterson, 1992).

A mother's asynchronous parenting style appears to be governed by either of two dispositions characterized as authoritarian or permissive (see Baumrind, 1971, 1983). The first of these entails harshness and demands for obedience, and the latter is more of a freedom oriented laxness in parenting - but both generate asynchrony and both can lead to coercion and a loss of mutual respect (i.e., Baumrind, 1973; Lahey, Conger, Atkeson, \& Treiber, 1984). Mothers with an authoritarian style seem prone to use aversive parenting tactics and, because of this bias, their corrective actions will challenge independence as well as antisocial behavior in their children. On the other hand, permissive mothers are biased in their positive outlook, leading them to encourage all child behavior, regardless of its adjustment value for the child.

If asynchrony in a mother-child interaction can be generated by the mother's authoritarian and permissive bias, either form of the inconsistency should foster child antisocial behavior (see the review by Shaw \& Bell, 1993). However, since the jury is still out on this matter, it would be important to make the appropriate comparisons to see if one of these maladaptive parenting styles is more closely associated with child conduct problems than is the other. In the present study, we attempted to do so within an investigation of child conduct problems in Spain and the USA (Cerezo \& D'Ocón, 1999; Cerezo, Wahler, \& Skinner, 1993). This investigation contrasts mothers' parenting role in Spain, along with the greater proportion of intact families in that country, compared with USA families (Gilmore, 1990; Iglesias de Ussel \& Flaquer, 1993; Meil-Landewerlin, 1998; Select Committee, 1989). Whereas there are marked family differences in the two countries, it does appear that asynchronous parenting is associated with child conduct problems across nationalities (Cerezo \& D’Ocón, 1999; Wahler, Williams, \& Cerezo, 1990). Whether or not the asynchrony also follows similar authoritarian and permissive parenting mistakes in these countries remains unknown, just as we are uncertain about the differential importance of these parental biases in the development of asynchrony and children's conduct problems.

Our operational definitions of authoritarian and permissive parenting were set within a molecular model of maladaptive parenting (Wahler \& Dumas, 1989), instead of Baumrind's (1971, 1983) molar conception of these parenting styles. Baumrind's comprehensive definitions were based on direct observations and parent interviews, with the data from both sources being classified into constructs by raters (e.g., Firm vs. Lax Enforcement Policy). In contrast, the Wahler and Dumas conception was based on 15-second intervals of observed behavior, summarized into appropriate or inappropriate parent reactions to child aversive and positive responses (Dumas \& Wahler, 1986; Wahler \& Dumas, 1986). The resultant index, reflecting a dimension of indiscriminate or asynchronous parenting, has been shown to co-vary with child antisocial behavior (see review by Wahler \& Dumas, 1989). A further refinement of the measure procedure, with observed behavior coded in real time supported those results (Cerezo \& D’Ocón, 1999; Wahler et al., 1990).

Following the basis of Wahler \& Dumas's (1989) study, we divided the asynchrony index into parents' inappropriate timing of aversive and positive reactions, with blanket use 
of aversive reactions being equated with an authoritarian bias and the same indiscriminate application of positive reactions viewed as permissive. Thus, a permissive parent would be disposed to offer positive reactions to all child behaviors, and thus tend to reward both prosocial and antisocial responses. This sort of parental indulgence, while not capturing the richness of Baumrind's (1971) permissive definition, does encompass a parent's tendency to endorse any form of child behavior. On the other hand, an authoritarian parent, by our definition, is unduly restrictive because of a demonstrated tendency to offer aversive reactions to all child behaviors. This parental disposition to be irritable and harsh, while opposite to the uncritical acceptance by our permissive parent, reflects the same failure to differentiate between the child's prosocial and antisocial responses.

The utility of studying conduct-problem children and their mothers in Spain and the USA is based on demographic differences in family composition and child-care, as well as through similarities in the role of asynchronous parenting. Certainly, the similarities suggest that further research might bring to light a common interpersonal process underlying family contributions to child psychopathology. Should a process emerge in this cross-cultural comparison, its presence across such diverse family samples would point to a robust quality of that process. Thus, the present study was conceived as a promising attempt to delineate the specific nature of asynchronous mother-child interactions associated with child conduct problems. Through home observations of clinic-referred and normal dyads in Spain and the USA, this study's goal was to determine the differential influence of authoritarian and permissive parenting on the child's status as conduct problem or normal. One hypothesis and one exploratory question guided our study. Thus, asynchronous parenting was expected to associate with child conduct problems across nationalities. The question was: Is one maladaptive parenting style more closely associated with child conduct problems than the other?

\section{Method}

\section{Participants}

Participants were 92 mother-child dyads from Valencia (Spain) and Knoxville (Tennessee, USA). Fifty-one of these were recruited in Valencia and the remaining 41 came from Knoxville. Recruitment began with the selection of clinical samples in each city, based on concerns about the children's conduct problems. In Valencia, 25 of these referrals were obtained through a social services agency responsible for child welfare. In Knoxville, 25 dyads came from public school and human service agencies. The recruitment strategy in both sites was based on maternal reports indicating concern about the children's conduct and the mothers' inability to manage or cope with these problems. The referral dyads also needed to be from socio economically disadvantaged families, as such a community sample is most apt to yield a homogenous picture of that community's cultural traditions. In return for the family's participation in this study, each was offered clinical services for the child's conduct problem.

The samples of normal dyads (26 in Valencia and 16 in Knoxville) were recruited by the authors through advertisements and through letters and phone calls to families who believed their children to be well adjusted. Once again, the focus was on socio economically disadvantaged families, with the intent of obtaining samples in both sites that differed only with respect to the children's social and emotional adjustment.

Mothers in the Valencia clinical sample $(n=25)$ ranged in age from 22 to 47 years $(M=34.17, S D=5.33)$ and indices of socioeconomic status placed them within a lower income category (average of 4 markers of socioeconomic disadvantage; $S D=1.16$; see Dumas \& Wahler, 1983, for descriptions of these markers). Fifteen percent of the mothers were single parents, 25 percent were employed in the community, and 12 percent utilized day care arrangements for their children in no-school hours. The referred children in this sample were largely males $(84 \%)$ and their ages ranged from 4 to 13 years $(M=8.72, S D=2.72)$. In each case, the social services referral was based on the child's chronic opposition to parental authority.

Based on these demographics and with help from the referral agencies, the contrast sample $(n=26)$ of untroubled children and their mothers was selected from the same Valencia neighborhoods. Selection criteria, in addition to the matching of demographics, were based on mother, school, and social agency reports reflecting the child's adequate adjustment.

Mothers in the Knoxville clinical sample $(n=25)$ ranged in age from 24 to 39 years $(M=32.09, S D=4.89)$ and indices of socioeconomic disadvantage placed them within a lower income category (average of 3.48 markers of socioeconomic disadvantage; $S D=.62$ ). Forty-two percent of the mothers were single parents, 70 percent were employed in the community, and 95 percent utilized day care arrangements (Boys and Girls Club, School After Care, Mother's Day Out) for their children. The referred children in this sample were largely male $(90 \%)$ and their ages ranged from 5 to 12 years $(M=8.23, S D=2.09)$. In each case, the social service or public school referral was based on the child's chronic opposition to parental authority.

The contrast sample $(n=16)$ of untroubled children and their mothers was selected from the same Knoxville neighborhoods. Selection criteria, in addition to the matching of demographics, were based on mother, school, and social agency reports reflecting the child's adequate adjustment.

A review of the subject characteristics in Valencia and Knoxville shows the samples to be similar in age, gender, 
and socioeconomic status. Whereas the mean number of socioeconomic disadvantage markers was higher in the Valencia sample, this difference was not statistically significant, $t(48)=1.834, p=.073$. In line with the differing cultures in these two cities, more of the Knoxville mothers were single parents, more of them were employed outside their homes, and more utilized day care arrangements, in no-school hours, in the care of their children.

\section{Instrument and Variables}

The measures of interest were direct observation codes comprising a well established coding system available in English and Spanish formats. This system, the Standardized Observation Codes, $3^{\text {rd }}$ Revision (SOC-III), has been available as an unpublished manual in the USA since 1986 (Cerezo, Keesler, Dunn, \& Wahler, 1986). The Spanish adaptation was published as a package in 1991 (Cerezo, 1991), and the updated package in a bilingual EnglishSpanish edition is now available in CD-ROM format (Cerezo, 2000). SOC-III is a multi-code template, enabling an observer to categorize on continuous basis, in real time, a child's behavior reflecting the youngster's solitary and social behavior, plus the reactions and cues provided by parents, siblings, and other family members; all of the coded social exchanges are rated for valence (neutral, positive, aversive). The psychometric properties of the USA SOCIII were summarized in a published dictionary (Cerezo, 1988), and the reliability and validity studies with both the English and the Spanish versions support its use (for a review see: Pons-Salvador \& Cerezo, 1991, and the section "What we have learned with the SOC-III" in Cerezo, 2000)

Consistent with previous research contrasting motherchild dyads in which the child is considered a conduct problem or well adjusted, our focus was on the social exchanges within dyads. Thus, following previous studies (Patterson, 1976; Snyder, Schrepferman, \& St.Peter, 1997; Wahler \& Dumas, 1986), we know that mothers of conduct problem children tend to be more indiscriminate or asynchronous in the timing of their positive and aversive responses. SOC-III yields a number of specific coded responses that can be grouped into categories reflecting these behaviors as follows:

1. Mother Positive Response (M+). This category included the codes mother positive social attention and positive instructions. In both codes, positive valence was scored for smiling, affectionate physical contact, voice tone, and verbal content.

2. Mother Aversive Response (M-). This category included the codes mother aversive social attention and aversive instructions. In both codes, aversive valence was scored for frowning, coercive physical contact, voice tone, and verbal content.

3. Child Positive Response $(\mathrm{Ch}+)$. This category included seven codes reflecting those behaviors considered desirable or prosocial by most parents: work, play, neutral social approach, positive social approach, positive instructions, neutral compliance, and positive compliance. Valence criteria were the same as those used for mothers and neutral valence was scored for those social responses not classified as positive or aversive.

4. Child Aversive Response (Ch-). This category included six codes reflecting those behaviors considered undesirable or deviant by most parents: complaints, rule violations, aversive social approach, aversive instructions, neutral opposition and aversive opposition. Valence criteria were the same as those used for mothers.

\section{Mother Asynchrony Based on Authoritarian and Permissive Biases}

The two categories reflected degree of maternal asynchrony in reactions to her child's positive and aversive behavior. In both cases, mothers' reactions were considered as appropriate or inappropriate based on our judgments about matching or mismatching valences (see, for details, Wahler \& Dumas, 1986; Cerezo \& Dolz, 2000). For example, if the child approaches mother in an aversive manner and mother responds in a positive way, this pair of codes would be considered a mismatch. Likewise, if the child is working on a household chore and mother responds in a positive manner, this pair of codes would be considered a match. The SOC III continuous observation is recorded in coding sheets with temporal marks every 15 seconds. For the purpose of this study, these 15 -second units were used as frames. Thus, matches and mismatches were tabulated within these units or, in cases where the child response occurred at the end of a unit, the first maternal response at the beginning of the next unit was used in these tabulations. In either case, any of the four combinations of matches and mismatches could not exceed one per unit. This rule of thumb was necessary to insure acceptable observer reliability.

Given the caveat that our consideration of matches and mismatches is debatable, authoritarian asynchrony was defined by mothers' inappropriate aversive reactions, whereas permissive asynchrony concerned inappropriate maternal positive reactions. Both forms of asynchrony were computed by the formula: number of mismatches divided by the number of matches and mismatches. As "number" referred to 15 -second time units, the asynchrony index was actually the proportion of mismatching units.

\section{Procedure}

In both cities, the home observations were scheduled and the ground rules were established in the same manner. The clinical dyads knew that our focus was on their coercive exchanges and the contrast dyads knew that our focus was 
on their adaptive exchanges. Including this "set," the two cross cultural samples were treated in an identical manner. Observations were scheduled for time of the day when all family members were likely to be together, television sets were to be turned off, phone calls were to be brief, extra family members were to be excluded, and all family members were to "do what they would normally do" at this time - with the encouragement to stay within two rooms of the house. Observations for clinical dyads occurred prior to the implementation of treatment strategies.

This study is based on 477 hours of coded behavior in naturalistic observation across the two samples. Observation sessions were one hour in length, and each dyad was observed for an average of 5.18 hours $(S D=1.89)$. The observers were college undergraduates who were trained in the use of SOC III until each observer could attain an $80 \%$ effective percent agreement across code scoring with the trainer (for details about the observers' standard training procedures, see Cerezo, 1991, 2000). Once the observers began their work, reliability sessions involving a "master" observer were scheduled at least once for each family.

\section{Results}

\section{Observer Reliability}

Inter-observer agreement in the scoring of SOC-III codes were examined by comparing observer reliability session records using the temporal marks on the stream of the otherwise continuous recording. The temporal marks provide a frame of 15 -second units, so this provided an interval-byinterval basis to compute reliability coefficients on a sessionby-session basis in reference to the category scores. Interval agreements were computed through kappa coefficients (Cohen, 1960) and session agreements were computed through intraclass correlation coefficients (see Winer, 1971, for calculation procedures). As Table 1 shows, the interval agreements (kappas) in both country samples were similar. According to the classification proposed by Fleiss (1981), kappa values between .40 and .60 are considered "acceptable," from .60 to .75 are "good," and those higher than .75 are "excellent." The interval agreement results were "acceptable" for $19 \%$ of the kappa values computed, "good" for $75 \%$ of the values, and "excellent for $6 \%$. Moreover, agreement (intraclass correlation coefficients) can be considered exceptional for the session scores of all positive and aversive behavior and the two composite categories describing maternal asynchrony (D’Ocón \& Cerezo, 1995). As these scores were used in the comparisons that follow, it is clear that these measures of interest were dependably scored by observers.

\section{Comparisons between the Spanish and USA Clinical and Normal Groups of Children}

As the selection of these groups was based on the subjective reports of referral agencies and mothers, one index of their validity could be obtained by comparing the two groups across countries on SOC-III measures relevant to the published norms on conduct problem versus nonclinical children (see Patterson, 1982, 1976). In essence, conduct problem children should behave in a more aversive and less positive manner than do normal children. Table 2 presents means and standard deviations for the clinical sample of conduct problem children and the comparison sample of normal children selected for study in Spain and in the USA.

Repeated measures ANOVAs on the child behavior measures support the validity of agency and mother judgments about these children. Across nations, the child clinical sample was more aversive, $F(1,88)=28.28, p<$ .001 , and less positive, $F(1,88)=6.37, p<.02$, than was the contrast sample. An inspection of the rate per minute output of these behaviors showed the clinical child sample to be aversive at a .43 average, whereas their normal

Table 1

Reliability of Four Code Groupings and Two Composite Categories Reflecting Mother and Child Behavior. Kappa Coefficients Describe 15-Second Interval Agreements Between Observations and The Intraclass Correlation Coefficients Describe Session Score Agreements. The Coefficients are Presented Separately for Clinical (C) and Normal (N) Dyads in Spain and the USA

\begin{tabular}{|c|c|c|c|c|c|c|c|c|}
\hline & \multicolumn{4}{|c|}{ Kappa Coefficients } & \multicolumn{4}{|c|}{ Intraclass Correlation Coefficients } \\
\hline & \multicolumn{2}{|c|}{ Spain } & \multicolumn{2}{|c|}{ USA } & \multicolumn{2}{|c|}{ Spain } & \multicolumn{2}{|c|}{ USA } \\
\hline & $\mathrm{C}$ & $\mathrm{N}$ & $\mathrm{C}$ & $\mathrm{N}$ & $\mathrm{C}$ & $\mathrm{N}$ & $\mathrm{C}$ & $\mathrm{N}$ \\
\hline Mother Positive Response & .61 & .50 & .65 & .70 & .89 & .96 & .85 & .91 \\
\hline Mother Aversive Response & .74 & .68 & .69 & .63 & .97 & .95 & .86 & .92 \\
\hline Child Positive Response & .76 & .75 & .70 & .64 & .97 & .99 & .93 & .87 \\
\hline Child Aversive Response & .65 & .50 & .60 & .71 & .98 & .97 & .93 & .87 \\
\hline Mother Asynchronous Aversive Reactions & - & - & - & - & .99 & .97 & .90 & .95 \\
\hline Mother Asynchronous Positive Reactions & - & - & - & - & .73 & .97 & .93 & .89 \\
\hline
\end{tabular}


Table 2

Means and Standard Deviations for 50 Conduct Problem Children (Clinical) and 42 Normal Children Selected in the USA and in Spain

\begin{tabular}{|c|c|c|c|c|c|}
\hline & & \multicolumn{2}{|c|}{ USA } & \multicolumn{2}{|c|}{ Spain } \\
\hline & & Mean & $\mathrm{SD}$ & Mean & $\mathrm{SD}$ \\
\hline \multirow{2}{*}{ Child Positive Behavior } & Clinical & 5.166 & 0.824 & 5.262 & 0.868 \\
\hline & Normal & 5.736 & 1.270 & 5.872 & 1.271 \\
\hline \multirow{2}{*}{ Child Aversive Behavior } & Clinical & 0.502 & 0.352 & 0.354 & 0.204 \\
\hline & Normal & 0.124 & 0.166 & 0.158 & 0.144 \\
\hline
\end{tabular}

counterparts did so at a .14 average. Likewise, the clinical children behaved positively at a 5.24 average, whereas their counterparts were slightly more positive at a 5.82 average.

The ANOVAS for nationality were not significant with respect to child aversive behavior, $F(1,88)=1.15, p=.29$, or with respect to child positive behavior, $F(1,88)=0.38$, $p=.54$. In addition, the interactions between nationality and adjustment status were not significant for child aversive behavior, $F(1,88)=2.92, p=.09$, or for child positive behavior, $F(1,88)=0.0001, p=.99$. Thus, given the significant and expected main effects for the clinical vs. normal samples across countries, it seems that the molar judgments by agencies and mothers about child conduct problems are valid and the child behavior under scrutiny was the same in Spain as it was in the USA.

Comparisons of Maternal Asynchrony with the Spanish and USA Clinical and Normal Groups of Children

Authoritarian asynchrony. Figure 1 presents some differences in maternal asynchronous aversive reactions involving both nationality and clinical status of the children. As the bar graphs indicate, the mothers of conduct problem children in both countries were more likely to mistime their aversive reactions, compared to the normal contrast groups. In addition, this form of maternal asynchrony appears to be more common in the Spanish groups than in their USA counterparts. ANOVAS confirmed both sets of mean differences through a nationality effect, $F(1,88)=10.78, p=.001$, and a clinical status effect, $F(1,88)=28.45, p=.0001$. As the interaction effect was nonsignificant, $F(1,88)=0.23, p$ $=.63$, there is no reason to believe that the nationality difference in asynchrony was differentially associated with the children's clinical status (e.g., that Spanish clinical mothers were more asynchronous than were USA clinical mothers). Thus, whereas it appears that Spanish mothers in Valencia held a more authoritarian bias than did USA mothers in Knoxville, this bias also differentiated the clinical and normal groups in the USA.

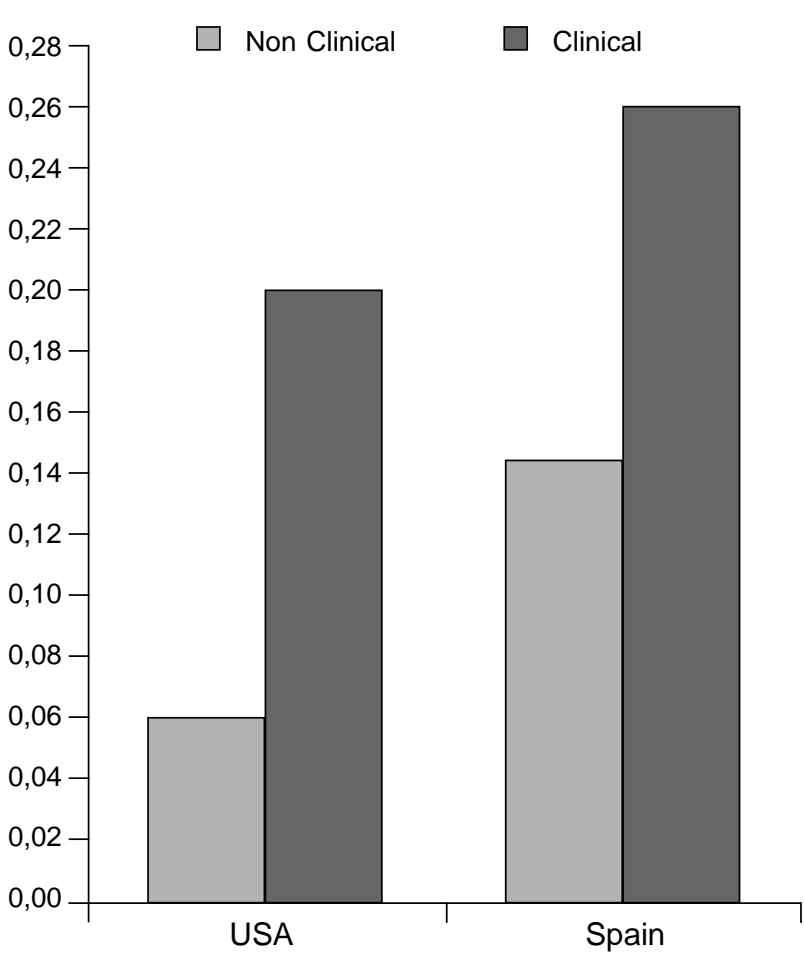

Figure 1. Mother's asynchronous aversive reactions.

Permissive asynchrony. Figure 2 presents some marked nationality differences in maternal asynchronous positive reactions, along with an absence of differences between the clinical and normal groups of both countries. The USA mothers of both conduct problem and normal children were far more likely to use positive attention indiscriminately than were their Spanish counterparts. However, it is also evident that this form of asynchrony had little association with the children's clinical/normal status in either country. Even in the USA samples, whose mothers were so prone to a blanket offering of positive responses, the asynchrony was virtually the same in both groups. Thus, in answer to our question about the role of permissive asynchrony in child conduct problems, there is no evidence here to support such a role. 


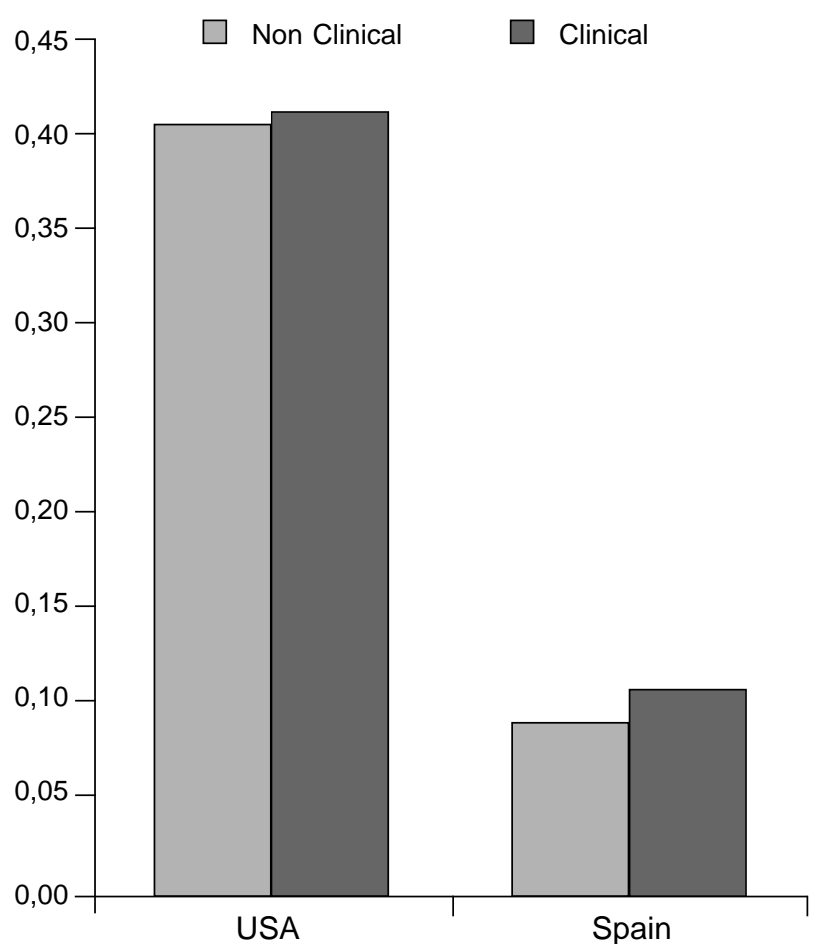

Figure 2. Mother's asynchronous positive reactions.

The ANOVAS for Figure 2 data revealed a significant effect for nationality, $F(1,88)=38.15, p=.0001$, a nonsignificant effect for clinical status, $F(1,88)=0.018, p$ $=.82$, and a nonsignificant interaction effect, $F(1,88), p=$ .89. In line with the bar graph depictions, the only significant difference in asynchrony involved nationality.

In an effort to shed further light on the nationality differences in authoritarian and permissive asynchrony, we conducted additional statistical comparisons involving several obvious differences in family demographics and maternal rates of aversive and positive attention. Concerning the rate issue, it is reasonable to think that the USA mothers' more frequent permissive asynchrony could simply be due to their tendencies to offer more positive reactions than their Spanish counterparts. Likewise, the Spanish mothers' more frequent authoritarian asynchrony could co-vary with their rates of aversive attention. Analyses of rates of maternal attention did indeed show that USA mothers were more positive with their children: USA mean rate $=.16 \mathrm{vs}$. Spanish rate $=.04, F(1,88)=23.90, p=.0001$. But, surprisingly, these USA mothers were also more aversive: USA mean rate $=.14$ vs. Spanish rate $=.07, \mathrm{~F}(1,88)=$ $7.87, p=.006$. By and large, the Spanish mothers were more reserved than their USA counterparts and we will have more to say about this finding in the discussion section. More to the point, there is no evidence to suggest that the nationality differences in maternal asynchrony were due to differential rates of maternal aversive and positive attention.
In reference to demographic factors in the national differences in maternal asynchrony, we wondered whether the higher proportion of single mothers in the USA samples might be associated with their permissive bias. This was based on our assumption that single parents could be less inclined to challenge their children than would a two-parent team, (Spanish single mothers $=15 \%$ vs. USA single mothers $=42 \%$ ). To pursue this hypothesis, we conducted the same mean comparisons of maternal asynchrony, this time, only considering the married mothers. However, results of the ANOVAS were virtually the same, with USA mothers displaying more permissive asynchrony, $F(1,62)=19.25$, $p=.0001$, and no difference in the clinical/normal comparison of permissive asynchrony, $F(1,62)=2.26, p=$ .14. Spanish mothers continued to show higher authoritarian asynchrony, $F(1,62)=20.59, p=.0001$, and the clinical groups showed higher asynchrony than the normal groups in both countries, $F(1,62)=11.22, p=.001$. Thus, there is no evidence to suggest that the national differences in maternal asynchrony were due to the differential proportions of single versus married mothers in the two countries.

\section{Discussion}

Congruent with previous research (e.g., Dumas \& Wahler, 1986; Cerezo \& D’Ocón, 1999; Patterson, 1976), the present findings show an association between maternal asynchrony and children's conduct problem status. Regarding the exploratory question, the results show that a mother's aversive attention is a more salient part of the asynchrony process than is her positive attention. In both the Spanish and USA samples, the mothers' asynchronous aversive reactions differentiated conduct-problem from normal children, whereas maternal positive asynchrony did not. Of course, asynchrony in a mother's aversive attention means that she has failed to pick out her child's prosocial responses as special occasions for her own positive responding. In her blanket, overly generalized use of aversive attention, she not only fails to encourage prosocial child behavior but she also creates chaos or uncertainty for her child. Under these social conditions, the child might well pursue aggression as the only viable means of obtaining predictability and perhaps the mother's compliance with his or her demands as well (Bank, Forgatch, Patterson, \& Fetrow, 1993; Cerezo \& D’Ocón, 1995; Cerezo, D’Ocón, Dolz, \& Cantero, 1995; Wahler et al., 1990).

Although it makes sense to find that a mother's authoritarian bias in asynchrony could lead to her child's conduct problems, the same theoretical case can be made for permissive asynchrony (e.g., Shaw \& Bell, 1993). The fact that this latter form of asynchrony was unrelated to child adjustment in either national sample is compelling as well as puzzling. We know that children, like adults, are apt to find aversive social stimuli to be more salient than positive 
stimuli (Gottman \& Rushe, 1993; Patterson, 1982), and perhaps it is this stronger eliciting function that accounts for the correlations under discussion. If the saliency hypothesis has merit, one ought to find that episodes of mother-child aversive asynchrony are more likely to set the occasion for child antisocial behavior than would positive asynchrony episodes. Wahler et al. (1990) found such a setting function for the general form of maternal asynchrony, but these investigators did not compare the setting power of its aversive and positive subcategories. Clearly, this comparison ought to be made along with an attempt to replicate the present correlational findings.

Whereas the nationality differences in maternal asynchrony and rates of maternal aversive and positive attention are intriguing cross-cultural contrasts, the small and singular samples in these two countries permit only guarded speculations, because the cases in this study come from just two cities, one American and one Spanish. Therefore, they can not claim to represent their respective countries. However, the USA mothers generated higher rates of both reactions and they were more likely to generate permissive asynchrony. In contrast, Spanish mothers were less social and more inclined to generate authoritarian asynchrony. Although we cannot point to factors that might account for these differences, the mothers themselves offered some viewpoints worth pursuing. In talking to them, we were impressed with nationality differences in their opinions about childcare. The Spanish mothers in both groups often cited expectations centering on the belief that children have to be encouraged to be independent and responsible for their own actions. According to these mothers, their parenting roles are largely geared toward giving their children the chance to first choose their behavior and insuring appropriate consequences for them later. As one mother put it, "There is no need to show him what to do, because he is the one who must decide. If I think he's wrong when he does it, I'll let him know, just as I'll let him know if he's right." On the other hand, the USA clinical and normal mothers were apt to portray an interdependence in which the children's responsibilities are modulated by family, peer, and school influences. These mothers seemed to downplay their personal power through references to siblings, peers, and the school. According to them, a parent's role is to be supportive by helping the child to sort out various choices in day-to-day life. As one mother put it, "He's got so much on his mind that I need to help him think things through. It's a complicated world out there."

Bearing in mind these subjective impressions, we wonder whether the differing rates of maternal attention and differing asynchrony biases might be some function of the mothers' differing conceptions of children and their needs. That is, the USA mothers obviously believed that children need direction and feedback and, while the Spanish mothers would agree, they also argued the importance of being judicious in the offering of either one. The USA mothers literally saturated their children with positive and aversive attention, compared to the Spanish mothers' offerings. Keep in mind that these latter mothers were less likely to be employed, less likely to utilize day care, and more likely to view themselves as solely in charge of their children (e.g., Iglesias de Ussel \& Flaquer, 1993; Select Committee, 1989). In contrasting these differing maternal roles, it is possible to imagine the two cultural patterns operating as quite different contextual determinants of parenting style.

For example, the USA mothers might have felt compelled to respond to their children because of the more limited parenting opportunities, whereas the Spanish mothers might not have felt this urgency. In following this speculation, the differential asynchrony biases could materialize out of this same "shared versus sole" authority in maternal roles. That is, when synchrony mistakes occur with mothers, they are apt to represent an exaggeration of one's natural parenting style. For Spanish mothers, that exaggeration would seem to entail power tactics, whereas USA mothers might pursue a guilt reduction strategy.

Whatever the validity of these speculations, they do not seem to have much bearing on the connection between parenting style and child conduct problems. Since authoritarian asynchrony proved directly associated with children's conduct problem status, one would have expected the Spanish clinical mothers to demonstrate this disposition to a greater degree than USA clinical mothers. Of course, the data showed otherwise, with the Spanish and USA mothers of conduct problem children being statistically similar and distinctively more asynchronous in their use of aversive attention than the normal mothers of both countries. Thus, even though the Spanish mothers were more prone to this form of asynchrony, having a conduct problem child seemed to override the cultural bias.

It could be argued that the differences found in this study between the conduct disordered and non-referred samples are not exclusive to this particular clinical problem, that is, a different clinical group might also be associated with a similar parenting style. To explore this aspect, future studies will require including more clinical groups.

\section{References}

Bank, L., Forgatch, M.S., Patterson, G.R., \& Fetrow, R.A. (1993). Parenting practices: Mediators of negative con textual factors. Journal of Marriage and the Family, 55, 371-384.

Baumrind, D. (1971). Current patterns of parental authority. Developmental Psychology Monographs, 4 (1, pt. 2).

Baumrind, D. (1973). The development of instrumental competence through socialization. In A. Pick (Ed.), Minnesota Symposia on Child Psychology (Vol. 7, pp. 3-46). Minneapolis, MN: University of Minnesota Press.

Baumrind, D. (1983). Rejoinder to Lewis' reinterpretation of parental firm control effects: Are authoritive families really harmonious? Psychological Bulletin, 94, 132-142. 
Bretherton, I., \& Waters, E. (Eds.). (1985). Growing points of attachment theory and research. Monographs of the Society for Research in Child Development, 50 (1-2, Serial Nr. 209).

Cerezo, M.A. (1988). Standardized Observation Codes: SOC. In M. Hersen \& A. Bellack (Eds.), Dictionary of behavioral assessment techniques (pp. 442-445). New York: Pergamon Press.

Cerezo, M.A. (1991). El entrenamiento de observadores en el SOC III [The observer training in SOC III]. In Cerezo, M.A. (Ed.), Interacciones familiares. Un sistema de evaluación observacional: SOC III. (pp. 59-95). Madrid: Mepsa. (revised and in bilingual English-Spanish version in M.A. Cerezo (Ed.), 2000.

Cerezo, M.A. (Ed.). (2000). Interacción familiar/Family interactionSOC III. (CD-ROM format). Valencia: Publicaciones de la Universidad de Valencia.

Cerezo, M.A., \& D’Ocón, A. (1995, November). The predictability hypothesis in coercive mother-child interaction. Sequential analyses of abusive Spanish mothers. Paper presented at the 29th Annual Conference for the Advancement of the Behavior Therapy. Washington, DC.

Cerezo M.A., \& D’Ocón A. (1999). Sequential analyses in coercive mother-child interaction: The predictability hypothesis in abusive vs. nonabusive dyads. Child Abuse and Neglect, 23, 99-113.

Cerezo, M.A., \& D’Ocón, A., Dolz, L., \& Cantero, M.J. (1995, May). Indiscriminate response to child's prosocial behavior in the abusive mothers: Its relationship with the child's deviant behavior in the home setting. Paper presented at the $5^{\text {th }}$ European Conference on Child Abuse and Neglect, Oslo, Norway.

Cerezo, M. A., \& Dolz, L. (2000). Análisis de datos. Medidas/ Data Analysis. Measurements. In M. A. Cerezo, (Ed.), Interacción familiar/Family Interaction- SOC III. (CD-ROM format). Valencia: Publicaciones de la Universidad de Valencia.

Cerezo, M.A., Keesler, T.Y., Dunn, S.E., \& Wahler, R.G. (1986). Standardized observation codes, $3^{\text {rd }}$ revision. SOC III. Unpublished manuscript. Department of Psychology. University of Tennessee.

Cerezo, M.A., \& Pons-Salvador, G. (1996). Ecosystem adversity as setting factors in mother's perception of child behavior and indiscriminate mothering. European Journal of Psychological Assessment, 12, 103-11.

Cerezo, M.A., Wahler, R.G., \& Skinner, L. (1993, November). Strategies in the mothering of conduct problem and normal children: Social cultural differences between Spain and the USA. Paper presented at the Association for the Advancement of Behavior Therapy, Atlanta, GA.

Cohen, J.A. (1960). Coefficient of agreement for nominal scales. Educational and Psychological Measurement, 20, 37-46.

Darling, N., \& Steinberg, L. (1993). Parenting style as context: An integrative model. Psychological Bulletin, 113, 487-496.

D’Ocón, A., \& Cerezo, M.A. (1995). La observación naturalista de la interacción familiar. Fiabilidad de las secuencias de eventos. Psicológica, 16, 367-384.
Dumas, J.E., \& Wahler, R.G. (1986). Indiscriminate mothering as a contextual factor in aggressive-oppositional child behavior. Journal of Abnormal Child Psychology, 13, 1-17.

Fleiss, J.L. (1981). Statistical methods for rates and proportions. New York: Wiley.

Gilmore, D.D. (1990). Manhood in the making: Cultural concepts of masculinity. New Haven, CT: Yale University Press.

Gottman, J.M., \& Rushe, R.H. (1993). The analysis of change: Issues, fallacies, and new ideas. Journal of Consulting \& Clinical Psychology, 61, 907-910.

Iglesias de Ussel, J., \& Flaquer, L. (1993). Familia y análisis sociológico: el caso de España. REIS: Revista Española de Investigaciones Sociológicas, 61, 57-75.

Instituto Nacional de Estadística (1991). Hogares. Resultados nacionales 1991. Madrid: Publicaciones del INE.

Kazdin, A.E. (1987). Conduct disorders in childhood and adolescence. Newbury Park, CA: Sage.

Kopp, C.B. (1982). Antecedents of self-regulation: A developmental perspective. Developmental Psychology, 18, 199-204.

Lahey, B.B., Conger, R., Atkeson, B.M., \& Treiber, F.A. (1984). Parenting behavior and emotional status of physically abusive mothers. Journal of Consulting and Clinical Psychology, 36, 252-256.

Loeber, R., \& Stouthamer-Loeber, M. (1986). Family factors as correlates and predictors of juvenile conduct problems and delinquency. In N. Morris \& M. Tonry (Eds.), Crime and justice: An annual review of research, 1 (pp. 29-149). Chicago: University of Chicago Press.

Lytton, H. (1990). Child effects—still unwelcome? Response to Dodge and Wahler. Developmental Psychology. 26, 705-709.

Maccoby, E.E., \& Martin, J.A. (1983). Socialization in the context of the family: Parent-child interaction. In P.H. Mussen (Series Ed.) \& E.M. Hetherington (Vol. Ed.), Handbook of child psychology: Vol. 4. Socialization. Personality and social development (pp. 1-102). New York: Wiley.

Meil-Landewerlin, G. (1998). La sociología de la familia en España, 1978/1998. REIS: Revista Española de Investigaciones Sociológicas, 83, 179-215.

Patterson, G.R. (1976). The aggressive child: Victim and architect of a coercive system. In E.J. Mash, L.A. Hamerlynck, \& L.C. Handy (Eds.), Behavior modification and families I. Theory and research (pp. 131-158). New York: Brunner/Mazel.

Patterson, G.R. (1982). Coercive family process. Eugene, OR: Castalia.

Patterson, G.R. (1992). Developmental changes in antisocial behavior. In R.D. Peters, R.J. McMahon, \& V.L. Quinsey (Eds.), Aggression and violence throughout the life span (pp. 52-82). Newbury Park, CA: Sage.

Patterson, G.R. (2002). Etiology and treatment of child and adolescent antisocial behavior. The Behavior Analyst Today, 3, 133-144.

Patterson, G.R., Reid, J.B., \& Dishion, T.J. (1992). A social learning approach: Antisocial boys. Eugene, OR: Castalia.

Pons-Salvador, G., \& Cerezo, M.A. (1991). Propiedades psicométricas del SOC III. In M.A. Cerezo (Ed.), Interacciones 
Familiares: Un sistema de evaluación observational: SOC III (pp. 95-128). Madrid: Mepsa. (revised and in bilingual EnglishSpanish version in M.A. Cerezo (Ed.), 2000.

Select Committee on Children, Youth \& Families, U.S. House of Representatives (1989). U.S. Children and their families: Current conditions. Washington, DC: U.S. Government Printing Office.

Shaw, D.S., \& Bell, R.Q. (1993). Developmental theories of parental contributors to antisocial behavior. Journal of Abnormal Child Psychology, 21, 493-518.

Snyder, J., Schrepferman, L., \& St.Peter, C. (1997). Origins of antisocial behavior: Negative reinforcement and affect dysregulation of behavior as socialization mechanisms in family interaction. Behavior Modification, 21, 187-215.

Vuchinich, S., Bank, L., \& Patterson, G. R. (1992). Parenting, peers, and the stability of antisocial behavior in preadolescent boys. Developmental Psychology, 28, 510-521.

Wahler, R. G. (1990). Some perceptual functions of social networks in coercive mother-child interactions. Journal of Social and Clinical Psychology, 2, 43-53.
Wahler, R.G., \& Dumas, J.E. (1986). Maintenance factors in coercive mother-child interactions: The compliance and predictability hypotheses. Journal of Applied Behavior Analysis, 19, 13-22.

Wahler, R.G., \& Dumas, J.E. (1989). Attentional problems in dysfunctional mother-child interactions: An interbehavioral model. Psychological Bulletin, 105, 116-130.

Wahler, R.G., Williams, A.J., \& Cerezo, A.M. (1990). The compliance and predictability hypotheses: Sequential and correlational analyses of coercive mother-child interactions. Behavior Assessment, 12, 391-407.

Westerman, M.A., \& Havstad, L.F. (1982). A pattern oriented model of caretaker-child interactions, psychopathology, and control. In K. Nelson (Ed.), Children's language (Vol. 3, pp. 204-246). Hillsdale, NJ: Erlbaum.

Winer, B.J. (1971). Statistical principles in experimental design ( $2^{\text {nd }}$ ed.). New York: McGraw Hill.

Received February 25, 2005 Review received March 9, 2005 Accepted March 29, 2005 